\title{
Understanding the Influence of Encapsulating Matrix on the Physical and Thermal Properties of Oregano Essential Oil Powder
}

\author{
Ariel Antonio Campos Toledo Hijo ${ }^{1}$, Joyce Maria Gomes da Costa1, Eric Keven Silva ${ }^{1 *}$,Viviane Machado Azevedo ${ }^{1}$, Maria \\ Irene Yoshida ${ }^{2}$, Soraia Vilela Borges ${ }^{1}$
}

${ }^{1}$ Food Science Department, Federal University of Lavras, 37200-000, Lavras, MG, Brazil

${ }^{2}$ Federal University of Minas Gerais, 37200-000, Belo Horizonte, MG, Brazil

Received: July 21, 2017; Accepted: September 28, 2017; Published:October 26, 2017

*Corresponding author: Eric Keven Silva, Food Science Department, Federal University of Lavras, 37200-000, Lavras, MG, Brazil, Tel: (+55 19 982833762); E-mail: engerickeven@gmail.com

\begin{abstract}
In this study, the influence of blends of carbohydrates on the physical and thermal properties of oregano essential oil micro particles was evaluated. Powders were produced by spray drying using different wall materials: gum Arabic (GA), modified starch (MS) and maltodextrin (MD). The micro particles were characterized by morphology, moisture content, water activity, particle size distribution, particle mean diameter, poly dispersity index, glass transition temperature $(\mathrm{Tg})$ and thermal stability. The partial replacement of GA by MS or a mixture of MS and MD resulted in micro particles with lower moisture content. The results showed that micro particles with GA had higher values of Tg (97.02 ${ }^{\circ} \mathrm{C}$ ), indicating more physical stability. However, the use of MS and MD results in a slight reduction of Tg. TGA results showed that the nature of wall materials have considerable effect on the thermal degradation of micro particles. Thermal analysis revealed the potential of application of these carbohydrates for substitution of GA.
\end{abstract}

Keywords: glass transition; gum Arabic; modified starch; microcapsules; thermal stability;

\section{Introduction}

The microencapsulation method via spray drying has been widely employed for encapsulation of essential oils and other flavors, due to the efficiency in the retention of volatile compounds and protection of the active compound against external agents, such as light and oxygen(Adamiec and Kalemba, 2006; Kha et al., 2014; Liu et al., 2001). In addition to their technical advantages (Liu et al., 2015), this technique allows the combination of encapsulating agents, including those with low cost, to produce higher quality products with lower production cost, which increases the industrial interest(Vaidya et al., 2006).

Essential oils are complex mixtures of fatty acids with long alkyl chain length and organic compounds with low molecular mass, such as esters, alcohols, phenols and others. They are commonly extracted from plants and spices through hydro distillation, mechanical process or by using solvents. These substances can have antioxidant and antimicrobial activity due to the high content of active compounds in their composition, such as terpenic ( $\alpha$-terpinene, limonene and terpinen-4-ol) and phenolic compounds (carvacrol and thymol), present in the oregano essential oil(Dambolena et al., 2010).The encapsulation techniques, such as spray drying are employed in order to produce stable products containing essential oils, because these substances exhibit chemical instability to temperature and humidity changes and contact with oxygen(Adamiec and Kalemba, 2006).

The study of the best combination of wall materials is of interesting order to maximize the retention of the active agent, as well asto obtain more stable particles. The properties of the encapsulating materials are the main factors that affect the microencapsulation efficiency (Gharsallaoui et al., 2007; Reineccius, 2004).Carbohydrates, including hydrolyzed and modified starches, gums, cellulose derivates and cyclodextrins, are commonly used in spray drying. Gum arabichas been the most common wall material used in the encapsulation of oils and flavors, since it has emulsifying properties and is excellent in the retention of volatiles(Da Costa et al., 2013; Fang et al., 2005; Fernandes et al., 2014; Toledo Hijo et al., 2014). Despite its excellent characteristics, in recent years, the gum Arabic has increased in cost, has limited availability and impurities (Gharsallaoui et al., 2007; Tonon et al., 2012).Thus, the study of encapsulants or combination of ingredients to replace the gum Arabic for microencapsulation has been encouraged.

In this context, the study of the effect of different encapsulating materials on the micro particle properties is an important subject. Modified starches and maltodextrins have shown to have excellent encapsulating abilities when combined with other materials, such as gum Arabic and proteins (Vaidya et al., 2006; Yoshii et al., 2001). Maltodextrins are partially hydrolyzed starch products formed by chains of D-glicose connected by $\alpha$ - 
$(1,4)$ bonds(Shahidi and Han, 1993). They are produced by acid or enzymatic hydrolysis of starches, or even a combination of both processes(Chronakis, 1998). The use of maltodextrin offers several advantages, such as low cost, high solubility, low viscosity and excellent protection of flavors against oxidation(CanoChauca et al., 2005; Goubet et al., 1998; Reineccius, 1991). Also, maltodextrins with high molarmass and low value of dextrose equivalent (DE) provide high physical stability to the wall matrix system(Bae and Lee, 2008).The modified starch is an encapsulating agent commonly used for their encapsulation abilities, such as excellent retention of volatiles (above 93\%), the stabilization of the emulsion and low viscosity(Arancibia et al., 2011). Capsul@, also known as octenylsuccinate starch, is a starch derivative obtained by starch esterification with octenylsuccinate anhydrous acid, resulting in a hydro phobically modified starch (Hui et al., 2009; Wang et al., 2011). Through this modification, the hydro phobicity of the octenylsuccinate is introduced and the hydro philicity of the starch is maintained. As a result, this starch derivative has been reported as an effective emulsifier(Wang et al., 2011) and is thus preferably used as an encapsulating agent in the microencapsulation process of foods.

The polymer association has become an alternative way for producing micro particles and it is highly demanded in many foods and pharmaceutical applications (Dalmoro et al., 2012; Vaidya et al., 2006).In fact, for ensuring and expanding the applicability of new particles in such fields, the study of their physical and thermal stability is required. However, these properties have not been fully evaluated. Therefore, the aim of this study was to evaluate blends of gum Arabic with maltodextrin and modified starch as a matrix system for microencapsulation of oregano essential oil by spray drying, in order to obtain a dried product with a high technological standard. The micro particles were characterized by moisture content, water activity, particle size distribution, particle mean diameter, poly dispersity index, morphology, glass transition temperature and thermal stability.

\section{Material and Methods}

\section{Material}

Oregano (Origanum vulgare L.) essential oil was purchased from Laszlo Aromatherapy Ltd (Belo Horizonte, MG, and Brazil) and used as the core material for the production of micro particles. Modified starch (Capsul - Snow Flake $₫$ E6131), donated by Corn Products (Mogi, SP, Brazil), maltodextrin (Globe® 1905 DE 20) and gum Arabic (Colloides Naturels SP, Brazil) were used as wall materials. In order to increase the capacity and stability of the emulsions or suspensions, we used modified starch, which modification consists of adding a lipophilic component (octenyl succinate) to the starch molecules.

\section{Experimental design}

The proportion of the wall materials were defined from the optimization reported by Da Costa et al. (2013)in order to obtain blends of carbohydrates with different concentration of GA (Table 1).

\begin{tabular}{|c|c|c|c|c|}
\hline \multicolumn{5}{|c|}{$\begin{array}{c}\text { Table 1: Proportions of wall materials for each treatment used as feed } \\
\text { solution for the spray drying process }\end{array}$} \\
\hline \multicolumn{5}{|c|}{ Proportions of wall materials (g/100 g) } \\
\hline Assay & Microparticles & $\begin{array}{c}\text { Gum Arabic } \\
\text { (GA) }\end{array}$ & $\begin{array}{c}\text { Modified } \\
\text { Starch } \\
\text { (MS) }\end{array}$ & $\begin{array}{c}\text { Maltodextrin } \\
\text { (MD) }\end{array}$ \\
\hline 1 & GA100 & 100 & 0 & 0 \\
\hline 2 & GA50:MS:MD & 50 & 25 & 25 \\
\hline 3 & GA25:MS & 25 & 75 & 0 \\
\hline 4 & GA25:MD & 25 & 0 & 75 \\
\hline 5 & GA25:MS:MD & 25 & 37.5 & 37.5 \\
\hline
\end{tabular}

\section{Production of oregano essential oil micro particles}

The emulsion was prepared by adding $90 \mathrm{~g}$ of wall materials and $10 \mathrm{ml}$ of oregano essential oil in $900 \mathrm{~mL}$ of distilled water. Maltodextrin and gum Arabic were hydrated in distilled water for 12 hours at 10 to $12{ }^{\circ} \mathrm{C}$. The respective wall materials were dissolved in distilled water at $60-70{ }^{\circ} \mathrm{C}$ using a homogenizer at a speed of 20,000 g-force for $30 \mathrm{~min}$. Then, modified starch was added at $82{ }^{\circ} \mathrm{C}$, maintaining homogeneity until complete dissolution of the wall materials. After complete dissolution of the encapsulants below $10{ }^{\circ} \mathrm{C}$, the oregano essential oil was added with full rotation of 20,000 g-force for 5 minutes.

The emulsion was submitted to drying using a LABMAQ Brazil spray dryer, Model MSD 1.0 (RibeirãoPreto, São Paulo, Brazil) equipped with a dual-fluid nozzle spraying system and an opening of 1.2×10-3 m. The inlet and outlet air temperatures were $180 \pm 2{ }^{\circ} \mathrm{C}$ and $105 \pm 2{ }^{\circ} \mathrm{C}$, respectively. The feed flow rate was adjusted to $2.97 \times 10-7 \mathrm{~m} 3 \mathrm{~s}-1$, the air flow inlet was maintained at $5.8 \times 10-4 \mathrm{~m} 3 \mathrm{~s}-1$ and the compressed air pressure to the spray flow was 5 bars.

The powder was collected and stored under refrigeration (4-7 ${ }^{\circ} \mathrm{C}$ ) in glass flasks protected from light and water vapor to avoid possible alterations in the material as well as agglomeration and oxidation until further analysis.

\section{Moisture content and water activity}

The moisture content was determined by gravimetric method according toAOAC (2000). The water activity $\left(\mathrm{a}_{\mathrm{w}}\right)$ was measured directly using a digital AQUALAB device (CX-2 model, Decagon Devices Inc., Pullman, WA) with controlled temperature (25 \pm 0.5 ${ }^{\circ} \mathrm{C}$ ). Each measurement was performed in triplicate.

\section{Morphology}

The particle morphology was evaluated by scanning electron microscopy (SEM). The powders were fixed on a piece of doublesided adhesive tape, mounted on SEM stubs with a diameter of $1 \mathrm{~cm}$ and a height of $1 \mathrm{~cm}$, coated with gold under vacuum and examined with a scanning electron microscope SEM 1430VP LEO (Electron Microscopy Ltd., Cambridge , UK). The microscope was operated at $20 \mathrm{kV}$ with magnifications from 900-1200. 


\section{Average diameter and particle size distribution}

The average diameter and particle size distribution were determined using a Master size 2000 laser light diffraction instrument (model Hydro 2000 MU, Malvern Instruments, Malvern, UK). A small sample of the powder was suspended in isopropyl alcohol p.a. (Synth) as a dispersing medium while stirring. The particle size distribution was monitored during each successive measurement until the measurements were constant. The average volumetric diameter (D4, 3) was measured, and the poly dispersity index (PDI) was calculated according to Equation (3) below:

$$
P D I=\left(\frac{d_{90}-d_{10}}{d_{50}}\right)
$$

Where, $d_{90} d_{50}$ and $d_{10}$ correspond to the average diameter equivalent to $90 \%, 50 \%$ and $10 \%$ of the cumulative volume, respectively.

\section{Thermal analysis}

\section{Differential scanning calorimetry (DSC)}

The micro particles were analyzed using a DSC calorimeter model 60-SHIMADZU (Shimadzu Corporation, Kyoto, Japan) to determine the glass transition temperature (Tg). Approximately 4-6 mg of sample was prepared in aluminum pans, while an empty pan was used as reference. The curve were obtained according to the follow heating program: samples were cooled from $25^{\circ} \mathrm{C}$ to $-70{ }^{\circ} \mathrm{C}$ and then heated from $-70{ }^{\circ} \mathrm{C}$ to $120^{\circ} \mathrm{C}$ at 10 ${ }^{\circ} \mathrm{C}$ min-1. The glass transition temperature ( $\mathrm{Tg}$ ) was obtained in the heating curve.

\section{Thermo gravimetric analysis (TGA)}

The thermal stability of the oregano essential oil micro particles was evaluated by thermo gravimetric analysis in a Shimadzu TG-DTA 50 H (Shimadzu Corporation, Kyoto, Japan) to quantify the mass loss of the powders. The analyses were performed under nitrogen at a flow rate of $50 \mathrm{~mL}$ min- 1 . The samples were heated at $10{ }^{\circ} \mathrm{C}$ min- 1 from $25{ }^{\circ} \mathrm{C}$ to $500{ }^{\circ} \mathrm{C}$ (Lavorgna et al., 2010).

\section{Results and Discussion}

\section{Moisture content and water activity}

Moisture content and water activity are important parameters for the characterization of particles, because they are directly related to the shelf life of foods. Through these parameters, it is possible to estimate the microbiological stability and storage conditions of dried foods. Micro particles of oregano essential oil presented values of water activity and moisture content between $0.1-0.18$ and $1.1-3 \%$, respectively (Table 2).The values of moisture content of micro particles are according to the minimum specification for most dried powders (3-4\%) and similar values were also found in studies on spray drying. Alvarenga Botrel et al. (2012)reported values of moisture content between 1.3 and $3.65 \%$ of microcapsules of oregano essential oil using gum Arabic, modified starch and maltodextrin as wall materials. According toBotrel et al. (2014), the drying conditions are the main factors affecting the moisture content of micro particles, although different encapsulating material can have significant effect. It was observed that micro particles containing higher concentration of modified starch (GA25:MS and GA25:MS:MD) showed lower values of water activity (0.10).This result can be related to the structure of the modified starch, because it has fewer hydrophilic groups compared with GA and MD. However, samples containing only GA (GA100) and their mixture with MD (GA25: MD) showed higher moisture content of $3 \%$. The hydrophilic branches present in the GA and MD structures contribute to the water adsorption, and consequently, to the increase in the moisture content.

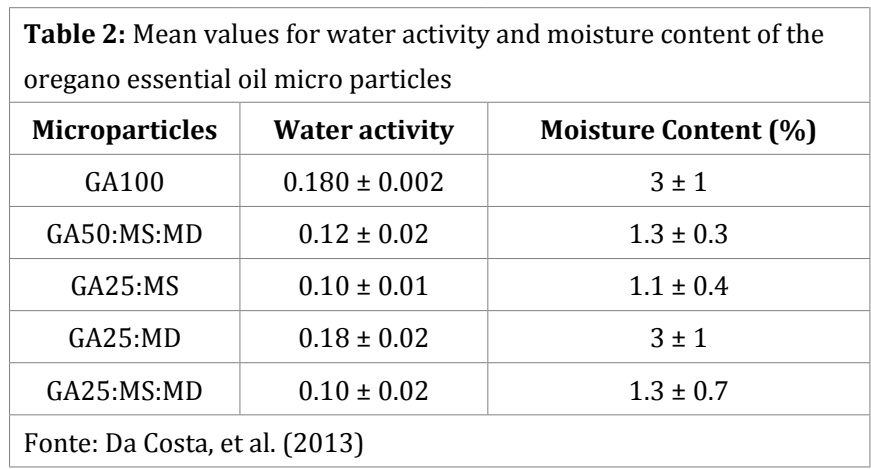

\section{Morphology and particle size distribution}

The scanning electron microscopic (SEM) images (Figure 1) showed that micro particles, for all samples, had an external topography characterized by spherical shapes with several sizes, no apparent pores, invaginations and continuous walls. Additionally, the micro particle structures had irregularities (depressions) on the surface. The formation of hollow particles is frequently observed in dried products by spray drying(Ré, 1998), and can be explained by the vacuoles produced inside the particles by the shrinking process that occurs after the development of the outer surface and the expansion of air trapped within the particles(Nijdam and Langrish, 2006; Ré, 1998). These imperfections on the surface of the particles have been reported by other authors and can be associated with the characteristics of the encapsulating agent and the conditions of the process(Alvarenga Botrel et al., 2012; Bertolini et al., 2001; Tonon et al., 2011; Trindade and Grosso, 2000).The mixture of different wall materials influences the morphology of the micro particles. However, no apparent differences in the surface characteristic of micro particles of oregano essential oil were observed. Janiszewska and Witrowa-Rajchert (2009) did not observe any differences in shapes of rosemary oil micro particles using different proportions of gum Arabic and maltodextrin as wall materials.

The integrality of the wall was evident for all samples, except for GA25: MS that showed cracks. This drawback does not ensure the protection of the core material and promotes permeability to oxygen and water vapor. Micro particles of essential oil that present cracks are susceptible to lose volatile compounds. 
Table 3: Diameters of micro particles produced with different wall materials. ${ }^{\text {a-d }}$ Letters represent a significant difference of $5 \%$ for the samples evaluated from different wall materials.

\begin{tabular}{|c|c|c|c|c|c|}
\hline Microparticle & $\mathbf{D}_{(\mathbf{0 . 1 )}}(\boldsymbol{\mu m})$ & $\mathbf{D}_{(\mathbf{0 . 5})}(\boldsymbol{\mu m})$ & $\mathbf{D}_{(\mathbf{0 . 9})}(\boldsymbol{\mu m})$ & $\mathbf{D}_{(\mathbf{4}, 3)}(\boldsymbol{\mu m})$ & PDI \\
\hline GA100 & $2.4 \pm 0.2$ & $8.1 \pm 0.3$ & $15.7 \pm 0.3$ & $8.5 \pm 0.2 \mathrm{~b}$ & $1.67 \pm 0.04$ \\
\hline GA50:MS:MD & $2.29 \pm 0.03$ & $8.7 \pm 0.1$ & $17.2 \pm 0.1$ & $9.3 \pm 0.1 \mathrm{c}$ & $1.72 \pm 0.01$ \\
\hline GA25:MS & $2.3 \pm 0.1$ & $8.3 \pm 0.3$ & $15.7 \pm 0.5$ & $7.8 \pm 0.3 \mathrm{a}$ & $1.63 \pm 0.01$ \\
\hline GA25:MD & $3.0 \pm 0.1$ & $10.5 \pm 0.1$ & $19.7 \pm 0.2$ & $11.0 \pm 0.1 \mathrm{~d}$ & $1.60 \pm 0.01$ \\
\hline GA25:MS:MD & $2.49 \pm 0.02$ & $9.1 \pm 0.1$ & $16.9 \pm 0.1$ & $9.0 \pm 0.1 \mathrm{c}$ & $1.627 \pm 0.003$ \\
\hline
\end{tabular}

Micro particles GA25: MD showed higher mean diameter, $11.0 \mu \mathrm{m}$, expressed by D [4, 3] (Brouckere mean diameter). When modified starch was used as wall material in micro particles GA25:MS, the size of the particles decreased and the mean diameter was $7.8 \mu \mathrm{m}$ (Table3).

The size of spray dried particles is affected by several factors, such as viscosity, concentration of encapsulating material and drying conditions(Jafari et al., 2008). According toJafari et al.(2008) high inlet temperatures in the drying process produces larger particles than those dried under conditions that result in slow drying. In addition, larger particles have higher encapsulation efficiency(Jafari et al., 2008).

The diameters of $8.5 \mu \mathrm{m}$ were obtained using only gum Arabic as an encapsulating material. These values were lower than those observed by Fernandes et al. (2014). The authors evaluated the effect of encapsulating materials in the microencapsulation of rosemary essential oil (Rosmarinus officinalis L.), and obtained higher average diameter values of $13.5 \mu \mathrm{m}$ with gum Arabic as an encapsulating agent and13.4 $\mu \mathrm{m}$ using starch in the process.

Values of $\mathrm{D}_{10}, \mathrm{D}_{50}$ and $\mathrm{D}_{90}$, which indicate diameters of $10 \%$, $50 \%$ and $90 \%$, respectively, of the volume of the group of micro particles, were determined (Table 3).The PDI of micro particles, calculated using the equation 3 , were low (1.60-1.72), which indicates a homogeneous distribution.

The histogram showed in (Figure 1) shows a bimodal behavior with two different peaks, each of which is the predominant diameter. This behavior is interesting considering the powder storage, since the population of smallest particles can penetrate into the spaces between the larger particles, occupying a smaller space.

\section{Differential scanning calorimetry (DSC)}

The transition from the solid glassy state to the semi-liquid gummy state of a micro particles occurs at the glass transition temperature (Tg)(Costa et al., 2015). The Tg is specific to each material and is affected by many factors, such as chemical structure, molecular weight and moisture content of the micro particles (Fernandes et al., 2014; Toledo Hijo et al., 2014).By knowing the Tg of amorphous materials, it is possible to predict storage and processing conditions of dried products. This is because above this temperature, physicochemical and structure changes, such as collapse, stickiness and micro particle rupture, can occur, and consequently, release of the active material (Botrel et al., 2014; Netto et al., 1998).

The DSC curves are shown in (Figure 2), representing the Tg of micro particles obtained from the midpoint of the glass transition range. The Tg determined by DSC analysis were $97.02{ }^{\circ} \mathrm{C}, 85.25$ ${ }^{\circ} \mathrm{C}, 96.58{ }^{\circ} \mathrm{C}, 94.61{ }^{\circ} \mathrm{C}$ and $84.55{ }^{\circ} \mathrm{C}$ for micro particles GA100, GA50:MS:MD, GA25:MS, GA25:MD and GA25:MS:MD, respectively. The micro particles with gum Arabic as wall material (GA100) showed higher values of $\operatorname{Tg}\left(97.02^{\circ} \mathrm{C}\right)$. According toBhandari and Howes (1999), among the solid components of amorphous dried foods, carbohydrates have more influence in the glass transition temperature. Wall materials that have high molar mass show high glass transition temperature. Thus, considering the materials studied in this work, GA has a higher molar mass(47,0003,000,000 g/mol)(Anderson, 1977), and consequently, a higher Tg compared with MD (DE 20) and MS, which have molar masses of $900 \mathrm{~g} / \mathrm{mol}($ Roos and Karel, 1991) and2,800,000 g/mol(Nilsson et al., 2006), respectively. The presence of GA in the encapsulating matrix of essential oil micro particles contributes for obtaining more stable products. This means that the higher the $\mathrm{Tg}$ of dried products, the higher their thermal stability, i.e., at temperatures above $97.02{ }^{\circ} \mathrm{C}$, the micro particles GA100 changed from the glassy state to the gummy state and changes in their structure occurred.

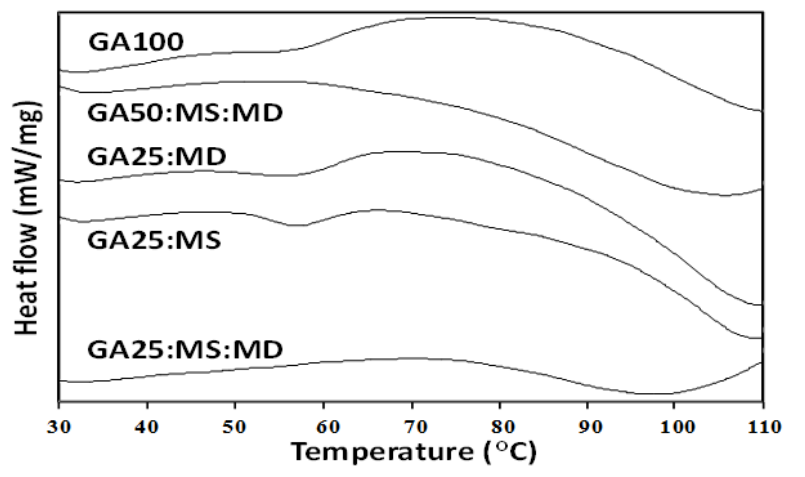

Figure 2: DSC curves obtained at heating temperature rate of $10^{\circ} \mathrm{C} \mathrm{min}{ }^{-1}$ for micro particles of oregano essential oil 

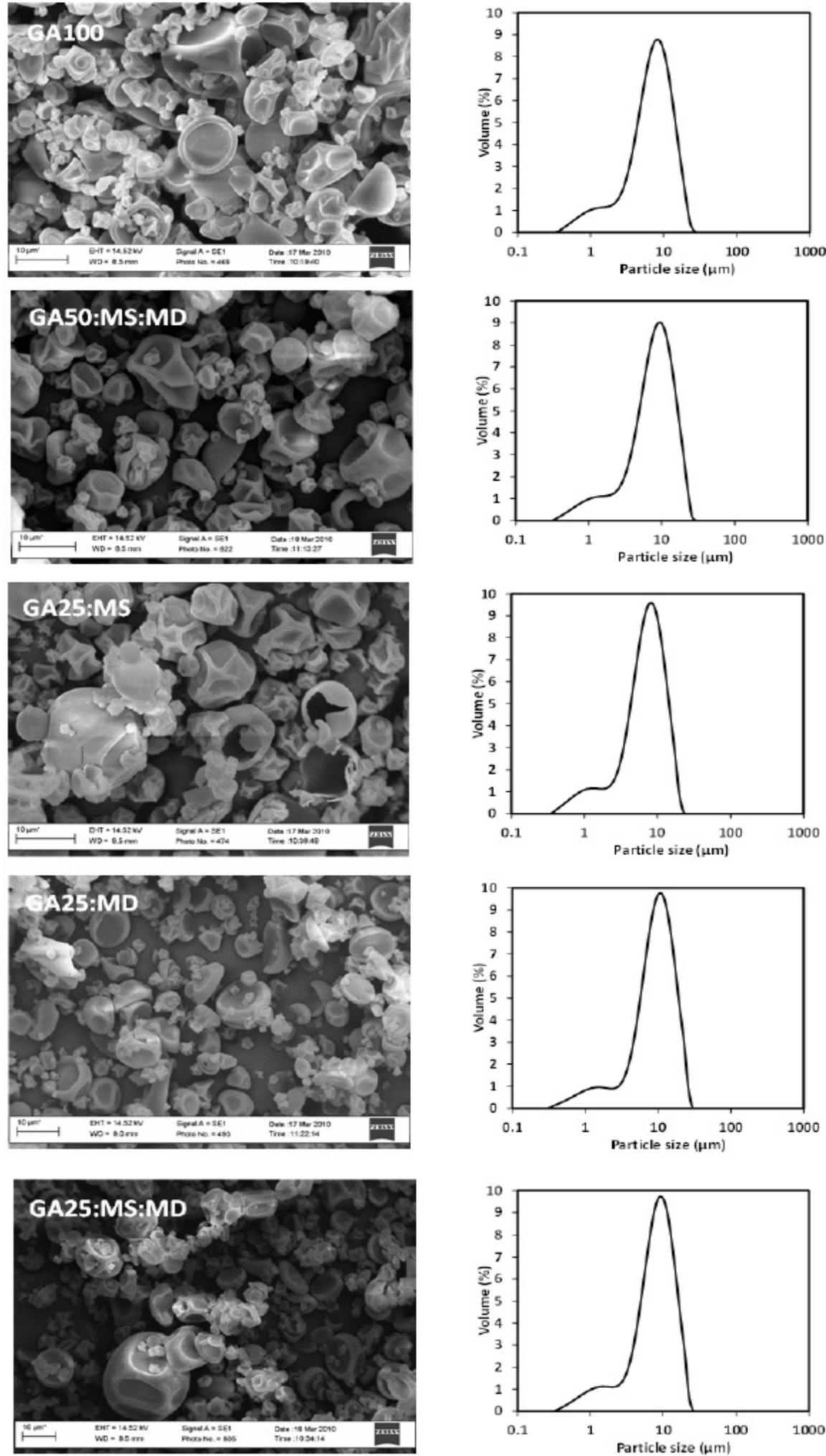

Figure 1:Morphology and particle size distribution of micro particles produced with different wall materials 


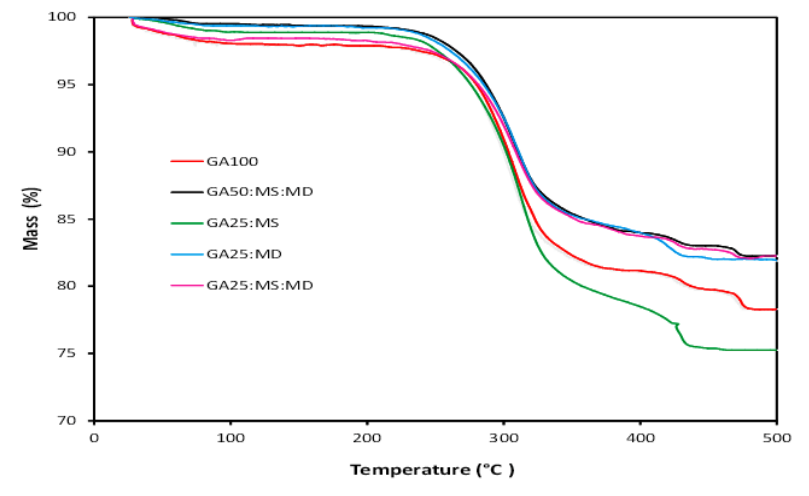

Figure 3: TGA curves for thermal decomposition of oregano essential oil micro particles

The use of MS and MD in the formulation of micro particles of oregano essential oil for the substitution of GA resulted in a slight reduction of Tg. However, GA25: MS and GA25: MD showed $\mathrm{Tg}$ values close to the $\mathrm{Tg}$ of micro particles containing only GA (GA100). This reveals that there is a potential for the application of MS and MD as wall materials as a substitution of GA in these concentrations, taking into account physical and thermal stability aspects. On the other hand, the use of MD and GA (GA25: MD) resulted in micro particles with lower $\mathrm{Tg}$ than those with MS and GA (GA25: MS) as wall materials. This difference is related to the lower molar mass of MD compared with MS, causing the opposite effect of GA(Fernandes et al., 2014).Toledo Hijo et al. (2014) studied the influence of water acting as plasticizer in the thermal properties of oregano essential oil micro particles stored at different relative humidity, containing GA and MS as wall materials and found Tg values between 91.29 and 164.47 ${ }^{\circ} \mathrm{C}$. However, studies evaluating the effect of wall materials on the thermal properties of micro particles of oregano essential oil were not found in the literature. Micro particles with MS, MD and GA (GA50: MS: MD and GA25:MS: MD)in their formulation showed the lowest values of $\mathrm{Tg}$, and as the concentration of GA decreased, their $\mathrm{Tg}$ also decreased, presenting a lower physical stability.

Considering the $\mathrm{Tg}$ as an indicator of micro particle stability in storage conditions(Bhandari and Howes, 1999; Ferrari et al., 2013), the micro particles of oregano essential oil were stable in storage at $25^{\circ} \mathrm{C}$, i.e., they remained in the glassy state (amorphous) at this temperature, which is lower than the glass transition temperatures of the micro particles studied in this work (between $84.55^{\circ} \mathrm{C}$ and $97.02{ }^{\circ} \mathrm{C}$ ).

\section{Thermo gravimetric analysis (TGA)}

The TGA thermo gram of the micro particles is shown in Figure 3. The thermal degradation of the samples showed three steps of $97.45 \%$ of mass loss in the $25-500{ }^{\circ} \mathrm{C}$ temperature range. Thermal decomposition of three steps of systems containing polymers similar than those used in this work has been reported by several authors(Janković, 2013; Liu et al., 2008; Mudgil et al., 2012). The results of TGA showed that the nature of the wall materials have considerable effect in the thermal degradation steps of micro particles. The first stage represents the evaporation or dehydration process from the start of heating until at temperature of $164{ }^{\circ} \mathrm{C}$ with $1.31 \%$ of average mass loss. At this stage, loss of water occurred corresponding to the critical moisture content, adsorbed volatile compounds or unencapsulated oil of micro particles. The micro particles GA25: MD and GA50: MS: MD showed higher initial degradation temperatures ( $\mathrm{T}_{\text {onset }}$ ) of 64.64 and $63.03{ }^{\circ} \mathrm{C}$ and lower percentage of mass loss of 0.62 and $0.63 \%\left(\mathrm{M}_{\text {loss }}\right)$, respectively. Micro particles that have a lower percentage of mass loss variation result in more stable products to thermal degradation(CANEVAROLO, 2003), indicating that the micro particles GA25:MD and GA50:MS:MD had higher thermal stability in the first step of thermal decomposition.

The second step of thermal decomposition occurred at the average temperature of $283.36^{\circ} \mathrm{C}$, showing the highest percentage of Mloss of $79.57 \%$.At temperatures between 194.71 and 372.00 ${ }^{\circ} \mathrm{C}$, the depolymerization process and thermal degradation of the wall material of micro particles occurred. Mudgil et al. (2012) reported thermal decomposition of guar gum at approximately $280{ }^{\circ} \mathrm{C}$. The thermal degradation temperature of starches has been reported by several authors to be approximately 300 ${ }^{\circ} \mathrm{C}$ (Guinesi et al., 2006; Liu et al., 2008; Soares et al., 2005). At this temperature a release of gases, such as $\mathrm{CO}_{2}, \mathrm{CO}$ and water occurred, due to the pyrolysis of the starch.

The third step of thermal decomposition corresponds to the oxidation of the organic matter or inert carbonaceous residues with an average loss of mass of $2.26 \%$ approximately at temperatures closed to $425.33^{\circ} \mathrm{C}$.

\section{Conclusion}

Lower water activity was obtained in micro particles containing higher concentration of modified starch (GA25: MS and GA25: MS: MD). The micro particles showed spherical shapes with irregularities on the surface. The DSC results showed that powders containing only GA as wall material presented higher physical stability, i.e., higher $\operatorname{Tg}\left(97.02{ }^{\circ} \mathrm{C}\right)$. However, MS (GA25:MS) and MD (GA25:MD) used as wall materials also presented high physical stability with $\mathrm{Tg}$ values of $96.58{ }^{\circ} \mathrm{C}$ and $94.61{ }^{\circ} \mathrm{C}$, respectively. TGA results presented three steps of thermal decomposition, commonly for carbohydrate polymers. Also, TGA thermo gram showed that the nature of biopolymers have considerable effect on the thermal degradation of oregano essential oil micro particles. The replacement of GA by MS or MD or the mixture of MS and MD is feasible. Thermal analysis revealed the potential of application of these biopolymers for substitution of GA.

\section{Acknowledgments}

The authors thank FAPEMIG (Research Support Foundation of the State of Minas Gerais) and CNPq (National Council for Scientific and Technological Development) for financial support and scholarships. 


\section{References}

1. Adamiec J, Kalemba D. Analysis of microencapsulation ability of essential oils during spray drying. Drying Technology. 2006;24(9):1127-1132.

2. Alvarenga Botrel D, Vilela Borges S, Victória de Barros Fernandes R, Dantas Viana A, Maria Gomes da Costa J, Reginaldo Marques G. Evaluation of spray drying conditions on properties of microencapsulated oregano essential oil. International Journal of Food Science and Technology. 2012;47(11):2289-2296. doi:10.1111/ j.1365-2621.2012.03100.x

3. Anderson DMW. Water soluble exudates. Part 1: Gum arabic. Process Biochemistry. 1977.

4. AOAC AoOACI. Official methods of analysis of the Association of Official Analytical Chemists, Gaithersburg: AOAC. 2000.

5. Arancibia C, Jublot L, Costell E, Bayarri S. Flavor release and sensory characteristics of $\mathrm{o} / \mathrm{w}$ emulsions. Influence of composition, microstructure and rheological behavior. Food Research International. 2011;44(6):1632-1641.

6. Bae EK, Lee SJ. Microencapsulation of avocado oil by spray drying using whey protein and maltodextrin. J Microencapsul. 2008;25(8):549560. doi:10.1080/02652040802075682

7. Bertolini AC, Siani AG, Grosso CR. Stability of monoterpenes encapsulated in gum arabic by spray-drying. J Agric Food Chem 2001;49(2):780-785.

8. Bhandari BR, Howes T. Implication of glass transition for the drying and stability of dried foods. Journal of Food Engineering. 1999;40(12):71-79.

9. Botrel DA, de Barros Fernandes RV, Borges SV, Yoshida MI. Influence of wall matrix systems on the properties of spray-dried microparticles containing fish oil. Food Research International. 2014;62:344-352.

10. CANEVAROLO Jr SV. Técnicas de caracterização de polímeros. Artliber São Paulo. 2003.

11.Cano-Chauca M, Stringheta PC, Ramos AM, Cal-Vidal J. Effect of the carriers on the microstructure of mango powder obtained by spray drying and its functional characterization. Innovative Food Science and Emerging Technologies. 2005;6(4):420-428.

12. Chronakis IS. On the molecular characteristics, compositiona properties, and structural-functional mechanisms of maltodextrins: A review. Crit Rev Food Sci Nutr. 1998;38(7):599-637. doi:10.1080/10408699891274327

13. Da Costa JMG, Silva EK, Toledo Hijo AAC, Azevedo VM, Borges SV. Physical and Thermal Stability of Spray-Dried Swiss cheese Bioaroma Powder. Drying Technology. 2015;33(3):346-354.

14. Da Costa JM, Borges SV, Hijo AA, Silva EK, Marques GR, Cirillo MA, et al. Matrix structure selection in the microparticles of essential oil oregano produced by spray dryer. J Microencapsul. 2013;30(8):717727. doi:10.3109/02652048.2013.778909

15. Dalmoro A, Barba AA, Lamberti G, D'Amore M. Intensifying the microencapsulation process: Ultrasonic atomization as an innovative approach. European Journal of Pharmaceutics and Biopharmaceutics. 2012;80(3):471-477.

16. Dambolena JS, Zunino MP, Lucini EI, Olmedo R, Banchio E, Bima PJ, Zygadlo JA. Total phenolic content, radical scavenging properties and essential oil composition of Origanum species from different populations. J Agric Food Chem. 2010;58(2):1115-1120.
17. Fang X, Shima M, Adachi S. Effects of drying conditions on the oxidation of linoleic acid encapsulated with gum arabic by spray-drying. Food Sci. Technol. Res. 2005;11(4):380-384.

18. Fernandes RV, Borges SV, Botrel DA. Gum arabic/starch/maltodextrin/ inulin as wall materials on the microencapsulation of rosemary essential oil. Carbohydr Polym. 2014;101:524-532. doi:10.1016/j. carbpol.2013.09.083

19. Ferrari CC, Marconi Germer SP, Alvim ID, de Aguirre JM. Storage Stability of Spray-Dried Blackberry Powder Produced with Maltodextrin or Gum Arabic. Drying Technology. 2013;31(4):470-478.

20. Gharsallaoui A, Roudaut G, Chambin O, Voilley A, Saurel R. Applications of spray-drying in microencapsulation of food ingredients: An overview. Food Research International. 2007;40(9):1107-1121.

21. Goubet I, Le Quere JL, Voilley AJ. Retention of Aroma Compounds by Carbohydrates: Influence of Their Physicochemical Characteristics and of Their Physical State. A Review. Journal of Agricultural and Food Chemistry. 1998;46(5):1981-1990.

22. Guinesi LS, da Róz AL, Corradini E, Mattoso LHC, Teixeira EdM, Curvelo AAdS. Kinetics of thermal degradation applied to starches from different botanical origins by non-isothermal procedures. Thermochimica Acta. 2006;447(2):190-196

23. Hui R, Qi-he C, Ming-liang F, Qiong X, Guo-qing H. Preparation and properties of octenyl succinic anhydride modified potato starch. Food Chemistry. 2009;114(1):81-86.

24. Jafari SM, Assadpoor E, He Y, Bhandari B. Encapsulation efficiency of food flavours and oils during spray drying. Drying Technology. 2008;26(7):816-835.

25. Janiszewska E, Witrowa-Rajchert D. The influence of powder morphology on the effect of rosemary aroma microencapsulation during spray drying. International Journal of Food Science and Technology. 2009;44(12):2438-2444. doi:10.1111/j.1365 2621.2009.02025.x

26. Janković B. Thermal characterization and detailed kinetic analysis of Cassava starch thermo-oxidative degradation. Carbohydr Polym. 2013;95(2):621-629. doi:10.1016/j.carbpol.2013.03.038

27. Kha TC, Nguyen MH, Roach PD, Stathopoulos CE. Microencapsulation of Gac Oil by Spray Drying: Optimization of Wall Material Concentration and Oil Load Using Response Surface Methodology. Drying Technology. 2014;32(4):385-397.

28. Lavorgna M, Piscitelli F, Mangiacapra P, Buonocore GG. Study of the combined effect of both clay and glycerol plasticizer on the properties of chitosan films. Carbohydrate Polymers. 2010;82(5):291-298.

29. Liu W, Chen XD, Selomulya C. On the spray drying of uniform functional microparticles. Particuology. 2015;22:1-12.

30. Liu X, Yu L, Liu H, Chen L, Li L. In situ thermal decomposition of starch with constant moisture in a sealed system. Polymer Degradation and Stability. 2008;93(1):260-262.

31. Liu XD, Atarashi T, Furuta T, Yoshii H, Aishima S, Ohkawara M, et al. Microencapsulation of emulsified hydrophobic flavors by spray drying. Drying Technology. 2001;19(7):1361-1374.

32. Mudgil D, Barak S, Khatkar BS. X-ray diffraction, IR spectroscopy and thermal characterization of partially hydrolyzed guar gum. Int J Biol Macromo. 2012;50(4):1035-1039.

33. Netto FM, Desobry SA, Labuza TP. Effect of water content on the glass transition, caking and stickiness of protein hydrolysates. International Journal of Food Properties. 1998;1(2):141-161. 
34. Nijdam JJ, Langrish TAG. The effect of surface composition on the functional properties of milk powders. Journal of Food Engineering. 2006;77(4):919-925.

35. Nilsson L, Leeman M, Wahlund KG, Bergenståhl B. Mechanical degradation and changes in conformation of hydrophobically modified starch. Biomacromolecules. 2006;7(9):2671-2679. doi:10.1021/ bm060367h

36. Ré MI. Microencapulsation of spray drying. Drying Technology 1998;16(6):1195-1236.

37. Reineccius GA. Carbohydrates for Flavor Encapsulation. Food Technology. 1991;45:144.

38. Reineccius GA. The spray drying of food flavors. Drying Technology 2004;22(6):1289-1324.

39. Roos YRJO, Karel M. Water And Molecular-Weight Effects On Glass Transitions In Amorphous Carbohydrates And Carbohydrate Solutions. Journal of Food Science. 1991;56(6):1676-1681.

40. Shahidi F, Han XQ. Encapsulation of Food Ingredients. Crit Rev Food Sci Nutr. 1993;33(6):501-547. doi: 10.1080/10408399309527645

41. Soares RMD, Lima AMF, Oliveira RVB, Pires ATN, Soldi V. Therma degradation of biodegradable edible films based on xanthan and starches from different sources. Polymer Degradation and Stability. 2005;90(3):449-454
42. Toledo Hijo AAC, da Costa JMG, Silva EK, Azevedo VM, Yoshida MI, Borges SV. Physical and Thermal Properties of Oregano (Origanum vulgare L.) Essential Oil Microparticles. Journal of Food Process Engineering. 2015;38(1):1-10.

43. Tonon RV, Grosso CRF, Hubinger MD. Influence of emulsion composition and inlet air temperature on the microencapsulation of flaxseed oil by spray drying. Food Research International. 2011;44(1):282-289.

44. Tonon RV, Pedro RB, Grosso CRF, Hubinger MD. Microencapsulation of Flaxseed Oil by Spray Drying: Effect of Oil Load and Type of Wall Material. Drying Technology. 2012;30(13):1491-1501.

45. Trindade MA, Grosso CR. The stability of ascorbic acid microencapsulated in granules of rice starch and in gum arabic. J Microencapsul. 2000;17(2):169-176.

46. Vaidya S, Bhosale R, Singhal RS. Microencapsulation of cinnamon oleoresin by spray drying using different wall materials. Drying Technology. 2006;24(8):983-992.

47. Wang X, Li X, Chen L, Xie F, Yu L, Li B. Preparation and characterisation of octenyl succinate starch as a delivery carrier for bioactive food components. Food Chemistry. 2011;126(3):1218-1225.

48. Yoshii H, Soottitantawat A, Liu XD, Atarashi T, Furuta T, Aishima S, et al. Flavor release from spray-dried maltodextrin/gum arabic or soy matrices as a function of storage relative humidity. Innovative Food Science and Emerging Technologies. 2001;2(1):55-61. 